\title{
Evidence-based dentistry at the FDI Meeting, Paris
}

\section{Asbjørn Jokstad}

Associate Professor, Institute of Clinical Dentistry, Dental Faculty, University of Oslo,
Norway

\begin{abstract}
Evidence-based dentistry is increasingly being discussed at major international conferences. The recent FDI World Conference at Paris in November was no exception. Two 3-hour workshop sessions on evidence-based dentistry were held.
\end{abstract}

Two sessions related to evidence-based dentistry (EBD) were organised during the annual meeting of the world dental federation, FDI, in Paris in the last week of November 2000.

FDI had organised a three-hour workshop, where a panel of five speakers presented several ongoing national and international EBD-activities to an audience of approximately 100 people.

Asbjørn Jokstad from the FDI commission introduced the topic by discussing if EBD is just another vogue in the dental academic world or should be considered as a powerful tool for busy practitioners to identify meaningful and relevant information in the maze of continually developing new materials and techniques in clinical dental practice.

The introduction was followed by a presentation of ongoing EBD activities. Nigel Pitts talked on behalf of the International Association for Dental Research (IADR), Derek Richards represented the Centre for Evidencebased Dentistry (CEBD), Oxford, UK and Helen Worthington together with Jan E Clarkson represented the Cochrane Oral Health Group (COHG) in Manchester, UK.

Nigel Pitts' examples of ongoing EBD activities were the programmes of the National Health System Research and Development (UK), the guideline development process in the Faculty of General Dental Practitioners (UK) and the Scottish Intercollegiate Guidelines Network (SIGN). The ongoing EBD activities in IADR were also described.

Derek Richards gave first a brief history of the CEBD and a description of the critical appraisal skills workshops that were to take place at the meeting. Other topics covered were a review of the CEBD website and the EvidenceBased Dentistry journal. He also described the Centre's future involvement in developing a database on critically appraised topics (CATs) and with the National Electronic Library for Health (UK).

Helen Worthington presented the COHG specialist register of RCT reports and how quality assessment of trials was carried out by the Cochrane Collaboration while Jan E Clarkson presented a splendid résumé of the background and outcomes of Cochrane systematic reviews she had been involved with entitled "Prevention and treatment of oral mucositis or oral candidiasis for patients with cancer".

All the speakers' presentations are located as powerpoint-slides on http: //www.odont.uio.no/prosthodont/ebd/. Parallel to the FDI workshop, ColgatePalmolive had organised a symposium entitled Evidence-Based Dentistry, where three speakers presented concrete examples of how EBD can best be used in everyday practice. The intention of the organiser was to demonstrate the value of the EBD approach to what dentists do everyday. Helen Worthington (Manchester) introduced the topic. Then Robin Davies (Colgate research scientist) presented a systematic review of triclosan containing toothpastes for plaque and gingivitis. The next two speakers, Philippe Bouchard (Paris) and Michael Noack (Køn) used the EBD approach to talk about nonsurgical periodontal treatment, restorative materials, and preventive measures for cosmetic restorations. The attendance was of about 150, consisting mainly of general practitioners from France. According to Colgate-Palmolive's director of professional relations, Christopher Fox, the company "has a great interest in EBD and sees the EBD approach as being an invaluable tool for the dental profession and ultimately being of great value to the patient".

An interesting detail was the variability of the French translations of the term "evidence-based dentistry". Three different translations of the term could be identified in the printed programme. It is apparent from discussions in nonEnglish journals that the most appropriate translation of the term creates problems in many other European 
languages. The French Cochrane Collaboration page use the term "médecine factuelle", which the FDI workshop adapted to "médecine dentaire factuelle". It would seem appropriate that this term should be employed.

The workshop had been given a slightly provocative title and the description in the meeting programme aimed to attract the major part of participants at the FDI world meetings, i.e. the general practitioners. To what degree this happened is uncertain. The auditorium was practically full, and several individuals appearing in the entrances throughout the session apparently changed their mind and did not enter. The audience appeared to consist of mainly dental officers and delegates from national dental associations.

The general impression from the two sessions was positive. It has therefore been decided that a new workshop on EBD will be arranged at this year's FDI world congress to be held in Kuala Lumpur, 27 September-1 October 2001 (http://www.fdi.org.uk). A major contractor to this workshop will be the newly opened Center for Evidence Based-Dentistry \& Dental Informatics in Davangere, India (http://www.cods.net/cebd/). 